\title{
Research on Enhancing the Actual Effects of Multimedia Teaching in Colleges and Universities
}

\author{
Xiaomei $\mathrm{Yu}^{1}$ \\ ${ }^{1}$ Experimental division; multimedia teaching; Liaodong University, Dandong, China \\ Correspondence: Xiaomei Yu, North Campus of Liaodong University, No.325 Jinshan Road, Jinshan Street, \\ Jinshan Town, Yuanbao District, Dandong, Liaoning, China. E-mail: zhangfang3699@163.com
}

Received: December 7, 2016

Accepted: December 28, 2016

Online Published: February 15, 2017

doi:10.5539/ass.v13n3p31

URL: http://dx.doi.org/10.5539/ass.v13n3p31

\begin{abstract}
Multimedia teaching is a basic means of teaching. It is an indispensable means to improve teaching quality and effect, to arouse the enthusiasm of students, and to enhance the learning atmosphere of classroom teaching. However, some multimedia practitioners have shortcomings and a one-sided understanding of multimedia teaching. This can reduce the practical benefits of multimedia teaching in colleges and universities.

This paper analyzes the problems and practical effects of multimedia teaching. It seeks to describe the current practices of multimedia teaching in colleges and universities, and puts forward some basic strategies to enhance its effectiveness for the information of multimedia users.
\end{abstract}

Keywords: actual effect; classroom teaching; higher education; multimedia

\section{Introduction}

As early as the mid-late 1940s, a wide range of multimedia teaching methods already existed. However, the level of science and technology was relatively low, with multimedia teaching restricted to playing slides or movies, mostly for science teaching. By the late 1980s, with the rapid development of educational science and technologies, multimedia teaching had undergone a significant qualitative change. Film, television, slide, projection, etc. were in wide-spread use in teaching at the time.

The adverse economic conditions in the 20th century constrained the promotion and widespread use of multimedia teaching. However, with the advent of the 21 st century, and China's rising national strength, the state's investment in multimedia education has increased year by year. It has become recognized as a necessary means of teaching, and its use is very widespread almost universal.

Multimedia teaching can be a double-edged sword. It improves the quality and effectiveness of teaching and mobilizes the enthusiasm of students to learn and activates classroom atmospherics. But, it can also bring problems where teachers rely entirely on multimedia classroom teaching. For example, if there is no multimedia component in the coursework or there are technological issues or power outages, teachers do not know how to complete lessons and teaching tasks. Additionally, some teachers replace physical experiments with the use of multimedia teaching. This does not allow students to fully experience the hands-on practicalities, and original purpose of experiments.

In order to solve the short-comings of multimedia teaching in colleges and universities, many domestic educators are actively studying and exploring how to enhance the practical effects of multimedia teaching, and have achieved beneficial results. For example, Guzong Yun and others discussed the problems and countermeasures of multimedia teaching in colleges and universities (Gu, Du, \& Yin, 2013); Chen Cuirong, Zhao Sa and others use the interview method to study and explore the problems and countermeasures of multimedia teaching (Chen, \& Zhao, 2013); Zheng Xining, The paper discusses the influence factors of multi-media teaching in colleges and universities (Zheng, Zhao, Chen, Zhang, \& Zhang, 2012), and discusses the effectiveness of multi-media teaching in Li Juan's ideological and political course (Li, 2013). These beneficial explorations of educators have played a role in promoting multimedia teaching practice and improving the practical effect of multimedia teaching. However, these studies and explorations of educators do not solve the problems of multimedia teaching in the majority of colleges and universities. Multimedia teaching in colleges and universities is still in a less than satisfactory state. Against this background, this paper analyzes problems and causes of current multimedia 
teaching in colleges and universities and puts forward concrete strategies to enhance the its effectiveness. The proposed strategies can improve the quality of current multimedia teaching in colleges and universities.

\section{Current Status of College Multimedia Teaching}

Multimedia teaching has become one of the most commonly used means of teaching and has been widely used in various areas of academia. The equipment most frequently used is audio, film, television and screen projection using computers and projectors. With the continual development of teaching methods and education technology more complex technologies are being adopted. These include computer and all-in-one display machines, multimedia spaces and integrated blackboards.

Such is the demand for multimedia equipment from courseware developers and college teachers that both groups suffer shortages of multimedia equipment and facilities. It is difficult to make a proper evaluation of the impacts of the shortages due to the lack of systematic and scientific evaluation measures.

\section{Multimedia Teaching Problems at Colleges and Universities}

\subsection{Problems at the Extremities of Teaching Methods}

The so-called problems at the extremities of multimedia teaching refer to either an over-reliance on multimedia in coursework, or its total absence, by a return to traditional blackboard and chalk teaching methods.

For the former, most of the university teachers are completely dependent on multimedia for delivering coursework. They feel that the use of multimedia is not only practical and logical, but it also to mobilizes the enthusiasm of students for classroom learning. They do not need to engage in a lot of blackboard writing or say a lot of words, as in the past. Through the use of multimedia, the teacher is able to concentrate on the course outline, focus, difficulties and important conclusions as they are presented on the projection screen for students. For these teachers, the key to maintaining normal teaching order is the availability and proper operation of multimedia teaching equipment, and the absence of power failure or outage. The inability to engage appropriate multimedia equipment in coursework presentation will prevent teachers completing teaching tasks and regimes.

For the latter, they primarily use a blackboard and chalk methodology to connect with the minds of students. The link is an indispensable means for teachers to improve teaching effectiveness. Therefore, they believe that no matter how good multimedia teaching methods are, there is no case for the absence of blackboard teaching.

In fact, teaching practice at both of the extremities is deficient. Whether it be only multimedia teaching, or traditional blackboard and chalk teaching, they are only a means to teach. In today's rapid development of modern educational technology, teachers can make full use of multimedia teaching methods to improve teaching effectiveness and yet still use traditional blackboard and chalk teaching. According to the theory of pedagogy, the choice of teachers' teaching methods mainly depends on the content and goals of the coursework, and the objectives of the teaching lesson. So, it is not to completely embrace multimedia teaching and abandon traditional blackboard teaching. Rather, it is to select the teaching medium that best achieves the highest teaching effectiveness whilst having regard to the nature of the coursework and the specific objectives of each teaching lesson.

\subsection{The Formalization of Multimedia Teaching}

Multimedia teaching involves the use of multimedia equipment to produce sound, symbols, text, images to students in the form of displays. It has the characteristics of fast propagation speed, large amounts of information and lifelike content. It seeks to immerse the viewer in a creative world of teaching. Many teachers favour multimedia teaching for its perceived superiority.

However, multimedia teaching is only a means to improve teaching efficiency. The form of any teaching method must be in line with the objectives and content of the coursework, and the objectives of the teaching lesson. There cannot be a simplified reliance on any multimedia tool for teaching efficiency without regard to these factors. For instance, video and images shown over a short period of time do not allow students enough time to think about the content of the teaching lesson. This is not an appropriate use of video or video services for classroom teaching because the display time is relatively short.

\subsection{The Problem of Multimedia Teaching Simulations}

One of reasons for the establishment of experimental courses in colleges and universities is to verify the knowledge, principles and laws of the existing disciplines. Secondly, it is to cultivate the ability of college students to solve practical problems. Experimental teaching is the key to develop college students and train students with hands-on abilities. In experimental teaching classes, these aims cannot always be successfully completed through the use of multimedia simulations. In these situations, the teaching of alternative multimedia 
teaching must be strictly controlled.

\subsection{The Evaluation of Multimedia Teaching Effectiveness}

The evaluation of the effects of multimedia teaching is a difficult process as there is no available objective, comprehensive and systematic evaluation indices. At present, evaluation of the effectiveness of multimedia teaching in colleges and universities relies solely on school teaching practitioners using after class qualitative evaluation indicators. These qualitative assessments are not reliable and depend on the educational experience, knowledge and subjective assessments of practitioners. The evaluation results will not support quantitative assessments and lose their scientific basis.

\subsection{Multimedia Teaching Management Issues}

The management of multimedia teaching in colleges and universities is spread amongst the school administration office, the modern education technology centre and the assets management department. This management framework leads to unclear responsibilities. And, if the communication and coordination mechanisms are poor, conflicts can arise.

From the perspective of school asset management, multimedia classroom equipment is managed by the Department of Assets, the Office of Academic Affairs, and Modern Education Technology Centre. Users may not bear relevant management or ownership responsibilities. In these situations, asset risk is heightened, and in the event of theft or other incidents, it may be difficult to determine offending parties.

\section{The Reasons for the Problems of Multimedia Teaching in Colleges and Universities}

\subsection{Failure to Understanding the Concept of Knowledge}

In the eyes of many teachers, multimedia teaching is a panacea that can be used to solve all the problems associated with knowledge transfer. As a result, many teachers adopt an extreme position in the use of multimedia teaching. In fact, there are no absolute truths in the regime of teaching. Any method or means is not a panacea, and attempting to use a sole teaching method or means to solve all issues is unrealistic.

Teaching methods and means for the purpose of knowledge transfer need to base on an evaluation of the objectives and content of the teaching lesson. In the final analysis, it can be said that problems associated with multimedia teaching arise, because teachers do not correctly understand the meaning of multimedia teaching.

\subsection{The Level of Teaching and Training Teachers Affects the Effectiveness of Multimedia Teaching}

The beneficial effects of multimedia teaching largely depend on courseware produced and utilized by teachers. As a result of modern education technology, and the availability of broader computer technologies, teachers do not encounter technological issues when developing courseware. However, problems can arise with the framework, structure, content, logic and other aspects of courseware development. In a general sense, multimedia courseware is equivalent to traditional teaching lesson plans. In traditional teaching an excellent teaching plan features clear purpose, focus, detail and appropriate structure. Multimedia courseware should also reflect the above characteristics. However, a number of factors are adversely affecting the quality of multimedia teaching courseware. These include teaching and training constraints, a lack of clear focus and structural development issues.

\subsection{Teacher Attitudes Can Create Problems in Multimedia Teaching}

Teaching is a form of creative labour that can demand excessive efforts in relation to its level of pay. Therefore, good quality teaching requires teachers who dare to sacrifice. However, there are some teachers who strive to gain more income using the philosophy of reciprocity as their guide. In these cases, they may use the development of multimedia teaching methods for their own private benefit.

\section{Enhance the Effectiveness of Multimedia Teaching in Colleges and Universities}

\subsection{Correctly Handle the Relationship between Traditional Blackboard Teaching and Multimedia Teaching}

Traditional blackboard teaching has a long history of development and it has accumulated a wealth of experience. So, it is important not to completely embrace multimedia teaching at the expense of traditional blackboard teaching. Rather, traditional teaching features excellent detailed teaching plans featuring purpose, focus and structure. These inherent characteristics should be adopted for the development of multimedia teaching courseware.

And, importantly, when it comes to selecting the teaching medium the aim should be to achieve the highest teaching effectiveness having regard to the nature of the coursework and each teaching lesson. 
Multimedia teaching is a modern teaching method. It uses the instrument, the equipment and the software to synthesize teaching content into sets of pictures. It also uses sound to create integrated teaching courseware that not only saves teaching time, but also enhances the teaching effect. Traditional blackboard teaching and multimedia teaching have their own merits and teachers must manage the relationship between the two. First of all, whether using traditional blackboard teaching or multimedia teaching, they are to complete the corresponding task of teaching. Secondly, the relationship between traditional blackboard teaching and multimedia teaching is not a subordinate one or a mutually exclusive one, it is a complementary one. Whichever you use will depend on the specific circumstances of the teaching task and its purpose.

\subsection{Grasp the Effectiveness of Multimedia Teaching}

Multimedia teaching must not be used just for its own sake. Multimedia teaching practitioners must understand the nature and purpose of teaching, and its fundamental principles. They must manage the duration of multimedia teaching classes, the use and frequency of video and audio, as well as the selection of pictures and other images. Otherwise, the entire classroom teaching will involve too much text, pictures, animation, sound interference that replaces the core teaching function. Multimedia courseware must give students the space to think, and promote positive thinking, and active student learning.

\subsection{Correctly Handle the Experimental Teaching of Multimedia Teaching Alternative}

Courses in colleges and universities that involve students in many physical and scientific experiments are designed to verify the knowledge, principles and laws of the existing disciplines. The teaching in these courses aims to promote the hands-on skills and practical abilities of students. When teaching these courses these aims cannot always be achieved through the use of multimedia simulations. In these situations, the use of alternative multimedia teaching must be strictly controlled to ensure that teaching plans and classes will address the needs of students.

\subsection{Construction of a Multimedia Teaching Effectiveness Evaluation System}

The evaluation of multimedia teaching effects suffers from the lack of an objective and comprehensive evaluation system. This paper suggests that colleges and universities should formulate an evaluation standard for multimedia teaching efficiency as soon as possible. It should involve qualitative evaluation techniques. The aim of this evaluation methodology should be to improve the quality of multimedia teaching. And, measures to improve the quality of multimedia teaching should include inspiring students to positive thinking and a broad understanding of the education process.

\subsection{Establish Clear Responsibilities for the Management of Multimedia Teaching}

There is a need to establish a management framework with clear lines of responsibility. In addition, colleges and universities should formulate corresponding management methods, and further clarify the management responsibilities of multimedia teaching. It is suggested that the classroom management of the multimedia teaching should be centralized in the modern educational technology and educational administration, and the office of academic affairs should be unified according to the teaching plan of the university. The quality of multimedia teaching should be managed by the Academic Affairs Office.

\section{Conclusion}

In summary, enhancing the effectiveness of multimedia teaching will not only involve improving the quality of school teaching requirements, but also cultivate high-quality personnel training needs. Universities and colleges should engage in greater efforts to improve multimedia teaching and ensure the quality of modern teaching practices.

\section{References}

Chen, C., \& Zhao, S. (2013). Problems and Countermeasures in Multimedia Teaching in Colleges and Universities - Analysis Based on Survey and Interview Method. Heilongjiang Higher Education Research, (5), 19-22. doi:10.3969/j.issn.1003-2614.2013.05.006

Gu, Z., Du, C., \& Yin, Y. (2013). Multi-media teaching problems and countermeasures. Contemporary Educational Theory and Practice, (2), 117-120. doi:10.3969/j.issn.1674-5884.2013.02.043

Li, J. (2013). College ideological and political theory course multimedia teaching effectiveness research. Reform and opening up, (24), 61-62. http://d.wanfangdata.com.cn/Periodical/ggykf201324037

Zheng, X., Zhao, Y., Chen, Z., Zhang, T., \& Zhang, Y. (2012). Modeling and Analysis of Influencing Factors of Multimedia Teaching in Universities. Applied Psychology, (1), 82-96. 
doi:10.3969/j.issn.1006-6020.2012.01.010

\section{Copyrights}

Copyright for this article is retained by the author(s), with first publication rights granted to the journal.

This is an open-access article distributed under the terms and conditions of the Creative Commons Attribution license (http://creativecommons.org/licenses/by/4.0/). 